\title{
Improving the management of potentially predictable hospital readmissions of the elderly and their quality of life through new ICTs
}

\author{
Francisco Ródenas \\ Polibienestar Research Institute - University of Valencia, Spain \\ francisco.rodenas@uv.es \\ Jorge Garcés \\ Polibienestar Research Institute - University of Valencia, Spain \\ Ascensión Doñate \\ Polibienestar Research Institute - University of Valencia, Spain
}

\begin{abstract}
The ageing population is currently beginning to create economic repercussions, as ageing often implies an increase of health expenditure related to, specially, hospital admissions and/or unplanned readmissions and long term care services. The present paper deals with two strategies that could be implemented through the establishment and use of new technologies to avoid these increasing costs: 1) screening tools of health information systems aimed at identifying patients at risk of hospital readmissions or repeated use of health resources; and 2) new ICTs at elderly homes to improve and monitor their quality of life. On the one hand, the screening tool The Community Assessment Risk Screen (CARS) has been tested in several health areas in the Valencian Community, Spain. On the other hand, the results obtained in this research topic are connected with the proposal of installing technologies at elderly homes through the project Smart technologies for self-service to seniors in social housing - HOST. This user-friendly technology is aimed at improving the quality of life of the elderly, to reinforce their social inclusion and to make possible they live for a longer period of time with independence in their houses. Thus, through new technologies the efficiency of social and health resources could improve, and it will contribute to optimize their use, their management, efficiency and the sustainability of current social protection systems.
\end{abstract}

Keywords: elderly, hospital readmissions, screening tools, ICTs, quality of life, CARs, health and social care, social sustainability

\section{Resumen}

Actualmente el envejecimiento de la población está dando lugar a repercusiones de tipo económico, pues implica un incremento del gasto sanitario asociado, especialmente, a ingresos hospitalarios $\mathrm{u}$ hospitalizaciones no planificadas, así como a cuidados de larga duración. En el presente artículo se tratan dos estrategias que podrían llevarse a cabo a través de la implementación y el uso de nuevas tecnologías con el objetivo de evitar el incremento en dicho tipo de gastos: 1) aplicación dentro de los sistemas de información sanitaria de herramientas de detección de pacientes con riesgo de sufrir reingresos hospitalarios o de hacer un uso repetido de recursos de tipo sanitario; y 2) nuevas TICs instaladas en las casas de personas mayores para mejorar y monitorizar su calidad de vida. Por una parte, se ha aplicado la herramienta The Community Assessment Risk Screen -CARS- en distintos departamentos de salud de la Comunidad Valenciana (España). Por otro lado, los resultados obtenidos en dicha investigación están estrechamente 
conectados con la propuesta de instalación de tecnologías en las casas de personas mayores que ofrece el proyecto Smart technologies for self-service to seniors in social housing - нозт. Esta tecnología fácil de usar está destinada a mejorar la calidad de vida de las personas mayores, a reforzar su inclusión social y a facilitar que puedan vivir durante más tiempo con independencia en sus hogares. De este modo, a través de las nuevas tecnologías, se podría mejorar la eficiencia de los recursos sociosanitarios, así como su coordinación y, finalmente, la sostenibilidad del sistema de protección social actual.

Palabras clave: mayores, hospitalizaciones de repetición, herramientas de cribaje, TIC, calidad de vida, CARs, asistencia sociosanitaria, sostenibilidad social

\section{Introduction}

Progress in several fields and contexts such as health care, standards of living or nutrition have contributed to an increase of life expectancy in western countries during recent decades. It is expected that there will be a considerable increase in the share of elderly people, especially those aged over 85 (Rechel et al., 2009). The ageing population represents a challenge for public authorities, policy makers, public and private business and the nonprofit sector due to its economic repercussions as ageing often implies an increase of health expenditure related to, for example, hospital admissions and/or unplanned readmissions and long term care services (Garcés \& Ródenas, in press).

To face up to the demographic and social effects associated with ageing in a timely and well planned manner, several and diverse responses and resources are required. In this sense, new solutions and approaches based on research and innovation play a crucial role in managing all the challenges that ageing and its repercussions imply now and in the future (Fuchsberger, 2008; Heinrich \& Karner, 2011; Paquette \& Xie, 2010). In the present paper we present two strategies to be implemented through the establishment and use of new technologies: 1) screening tools in health information systems aimed to identify patients at risk of hospital readmissions or repeated use of health resources; and 2) new ICTs at elderly homes to improve and monitor their quality of life.

On the one hand, the elderly represent a group of population with a high risk of repeated use of healthcare resources, as primary care and emer- gency department (ED) visits, or hospital readmissions (Aminzadeh \& Dalziel, 2002; Dobrzanska \& Newell, 2006). Thus, nowadays there are several tools aimed to screen elderly people with high risk of suffering readmissions that facilitate their identification and, consequently, the application of care programs aimed to prevent or delay these relapses (Newcomer et al., 2004; Shepperd et al., 2008; Shepperd et al., 2009).

Through computerized health administration data it is possible to collect and check relevant clinical and socio-demographic factors from patients that makes it easier their early identification and intervention if it were necessary (e.g. Crane et al., 2010; Votja et al., 2001). In that respect, we have tested a screening tool, The Community Assessment Risk Screen - CARs (Shelton et al., 2000), in health information systems to identify elderly patients at risk of hospital readmissions or repeated use of health resources in Valencia (Spain). The CARs includes 3 factors to predict future hospitalizations: preexisting chronic diseases (heart disease, diabetes, myocardial infarction, stroke, chronic obstructive pulmonary disease-COPD- or cancer), the number of prescription medications and hospitalizations or ED use in the preceding 6 months.

On the other hand, a new ICT service for elderly homes is being developed through a cross-national project called Smart technologies for self-service to seniors in social housing -HOST- (www.hostaal.eu), which provides easy-to-use technologies and services in social housing flats to allow a better quality of communication and a better access to package services for the elderly; by experimenting with a European model of "connected flats" 


\section{hesSt Principles underlyng the proposal}

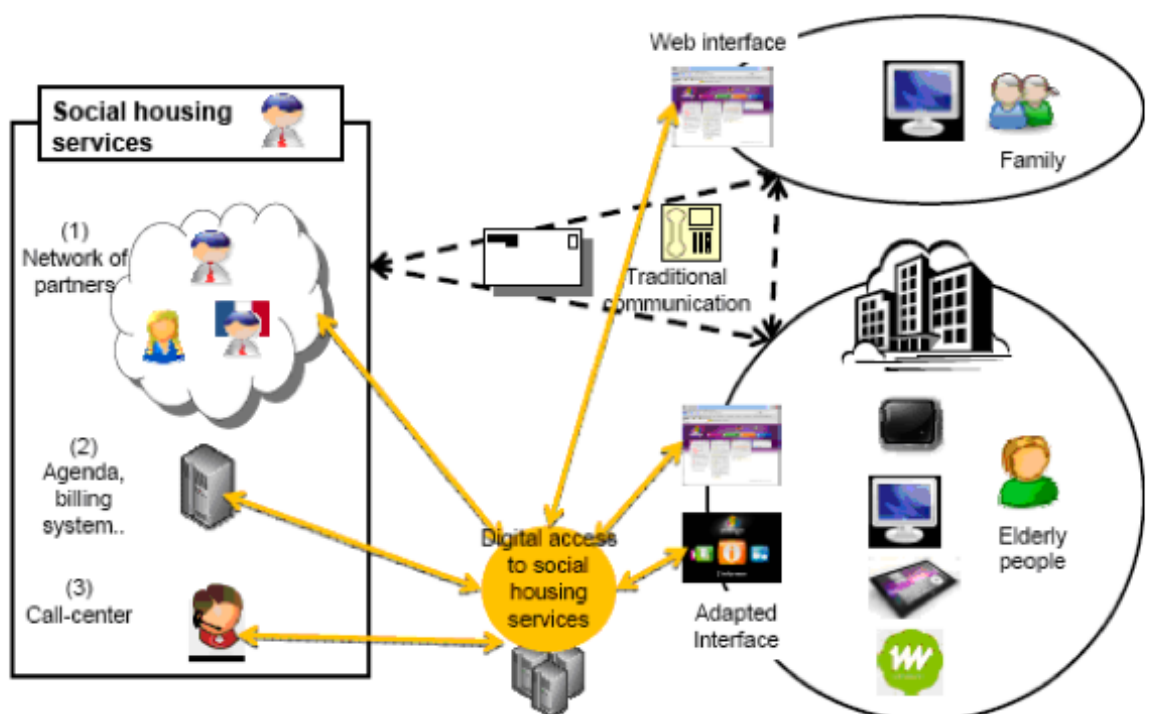

Figure 1. HOST technologies and services ming the points of each question, with a possible range of 0 to 9 . So, patients with a total score of 4 or higher are classified in the high risk group, and those with a smaller score than 4 are classified in the low risk group.

The data from the instrument and the search of hospital admissions of each patient were collected through several Spanish healthcare databases: SIA-Abucasis and Hospital MDs (Minimum Data Set), with respect to 2008 and 2009. Statistical analysis was performed using SPSS $^{\mathrm{TM}} 17$ software. for elderly people. This service is characterised by specific equipment enabling easier relations with family, service providers and housing operators, through enriched supports (images, text, voice, documents).

So, the objective of this paper is to present the results from two different but associated projects aimed to improve the management of elderly patients in primary health care systems and improve their quality of life at home.

\section{Methodology}

\subsection{Application of CARS instrument}

The target population of this study were patients 65 years or older who were attended to in the Valencian Healthcare System, from a total population of 153,895 in three health departments (Conselleria de Sanitat, 2009). Hospitalization risk was evaluated through The Community Assessment Risk Screen (CARS), which provides a total score by sum-

Table 1. Operating characteristics Source: Polibienestar Research Institute (2011)

\begin{tabular}{|l|l|}
\hline Sensitivity & Specificity \\
\hline $64 \%$ & $64 \%$ \\
\hline
\end{tabular}

\subsection{HOST technology and services}

The main target population of the HOST project is elderly people living in social houses and their caregivers from France, Italy and United Kingdom.

The HosT project will provide easy-to-use technologies and services in housing (see Figure 1):

- TV-based ICT devices (a box) allowing oral, textual and visual connections between the elderly and their "circle of relation-relatives".

- A specific added screen could fit both an exit scenario or a second channel of access if the TV set does not fit all the necessary requirements (regarding the usage of users).

- Different interfaces (handset and navigation scenarios) will be experimented jointly on an open IP technology to ensure a friendly and easy to use environment.

\section{Results}

\subsection{Diagnostic accuracy of CARs test}

Five hundred subjects with complete cARs instrument were used for this analysis. Table 1 shows the sensitivity and specificity of the tool. 
Moreover, the average number of admissions in 2009 and the mean hospital length of stay were statistically significantly different across CARs high and low risk groups ( $\mathrm{p}<0.001$ in both cases).

\subsection{HOST service}

The HOST project has the potential to help elderly people to access innovative devices and contents, under the responsibility of social housing landlords. The challenge to equip individual flats and collective residences and to allow the elderly to get an adequate level of self-service represents a huge market potential. So, the expected results and impacts of the HOST service for the elderly after their establishment will be:

- To bring more comfort of living.

- To reinforce social inclusion (with friends, family, administrations, social operators...).

- To allow a longer stay in their houses.

\section{Conclusions and future directions}

New technologies have a great impact on the improvement of social and health care and resources addressed, in this case, to elderly population.

On the one hand, through the application of risk screening tools at health information systems, such as CARs, it is possible to detect the frailty of the elderly and, therefore, to avoid potential and predictable hospital readmissions. Our study carried out showed that the CARs tool performed with moderate efficiency, sensitivity and specificity values of $64 \%$. These results suggest that this instrument is of interest to the Spanish healthcare administrations, as the application of instruments of this kind could be a good strategy to improve healthcare policies and, consequently, to optimize their use, their management and the sustainability of current social protection system (Garcés et al., 2011; Garcés, in press). On the other hand, the establishment of new technologies and services from HOST project addressed specifically to the elderly at their homes provides monitoring through their "circle of relation-relatives", as well as implying support for their caregivers by avoiding negative repercussions related to informal care (Carretero et al., 2009), and facilitates communication with their family, service providers and housing operators.

The combination of these two types of innovative resources and tools has a great potential to encourage the adoption of good practices by governments and administrations by facilitating the early detection of the frailty of elderly patients, the prevention of relapses and avoidable hospital readmissions, as well as the promotion of health through the monitoring of patients at their own homes.

\section{Acknowledgements}

The studies presented in this paper received financing from the Ministry of Science and Innovation, through the Spanish National R+D+I Plan (20082011) (Project reference: CSO2009-12086); from the Generalitat Valenciana, project Prometeo-OpDepTec (Project reference: PROMETEO/2010/065); Valencia Health Agency of Ministry of Health of Valencia 2010; and from Ambient Assisted Living Program and Instituto de Salud Carlos III (Project Reference: AAL-2010-3-041).Vojta, C. L.; Vojta, D. D.; TenHave, T. R.; Amaya, M.; LavizzoMourey, R. \& Asch, D. A. (2001). Risk screening in a medicare/medicaid population administrative data versus self report. Journal of General Internal Medicine, 16(8), 525-530. 


\section{References}

Aminzadeh, F. \& Dalziel, W. B. (2002). Older adults in the emergency department: a systematic review of patterns of use, adverse outcomes, and effectiveness of interventions. Ann Emerg Med., 39: 238-47.

Carretero, S., Garcés, J., Ródenas, F. \& Sanjosé, V. (2009). The informal caregiver’s burden of dependent people: Theory and empirical review. Archives of Gerontology and Geriatrics, 49(1): 74-79.

Conselleria de Sanitat (2009). Informe del Sistema de Información Poblacional de la Comunidad Valenciana. Available at: http://www.san.gva.es/docs/InformeNov09EstudioNoEmp08.pdf

Crane, S. J., Tung, E. E., Hanson, G. J., Cha, S., Chaudhry, R. \& Takahashi, P.Y. (2010). Use of an electronic administrative database to identify older community dwelling adults at high-risk for hospitalization or emergency department visits: The elders risk assessment index. BMC Health Services Research, 10: 310-338.

Dobrzanska, L. \& Newell, R. (2006). Readmissions: a primary care examination of reasons for readmission of older people and possible readmission risk factors. Journal of Clinical Nursing, 15: 599-606.

Fuchsberger, V. (2008). Ambient assisted living: elderly people's needs and how to face them. SAME '08 Proceedings of the 1st ACM International Workshop on Semantic Ambient Media Experiences. New York (USA).

Garcés, J., Carretero, S. \& Ródenas, F. (2011). Readings of the social sustainability theory. Tirant lo Blanch, Valencia (Spain).

Garcés, J. \& Ródenas, F. (in press). Sustainable social and health care transitions in advanced welfare states. In: Broerse, J. \& Grin, J.: Towards system innovations in health systems: Understanding historical evolution, innovative practices and opportunities for a transition in healthcare, Part II. Innovation practices: Experiences and lessons. Routledge, New York (USA).

Garcés, J. (in press). Sustainability and transformation in European social policy. Peter Lang Ltd., Oxford (United Kingdom).

Heinrich, C. \& Karner, K. (2011). Ways to Optimize Understanding Health Related Information: The Patients' Perspective. Geriatric Nursing, 32(1): 29-38.

Newcomer, R., Maravilla, V., Faculjak, P. \& Graves, M. T. (2004). Outcomes of preventive case management among high-risk elderly in three medical groups: A randomized clinical trial. Evaluation \& the Health Professions, 27(4), 323-348.

Paquette, S. \& Xie, B. (2010). The Relevance of Elderly Technology Users in Healthcare Knowledge Creation and Innovation: A Case Study. Proceedings of the 43rd Hawaii International Conference on System Sciences. IEEE Computer Society, Hawaii (USA).

Rechel, B., Doyle, Y., Grundy, E. \& McKee, M. (2009). How can health systems respond to population ageing? World Health Organization 2009 and World Health Organization, on behalf of the European Observatory on Health Systems and Policies $n^{\circ} 10$.

Shelton, P., Sager, M. A., \& Schraeder, C. (2000). The community assessment risk screen (cars): Identifying elderly persons at risk for hospitalization or emergency department visit. The American Journal of Managed Care, 6(8), 925933.

Shepperd, S., Doll, H., Angus, R. M., Clarke, M. J., Iliffe, S., Kalra, L., et al. (2009). Avoiding hospital admission through provision of hospital care at home: A systematic review and meta-analysis of individual patient data. CMAJ: Canadian Medical Association Journal = Journal De l'Association Medicale Canadienne, 180(2), 175-182.

(2008). Admission avoidance hospital at home. Cochrane Database of Systematic Reviews (Online), (4)(4), CD007491. 